\title{
BMJ Open Sex differences and correlates of poor glycaemic control in type 2 diabetes: a cross-sectional study in Brazil and Venezuela
}

\author{
Fernanda G Duarte, ${ }^{1}$ Sandra da Silva Moreira, ${ }^{2,3}$ Maria da Conceição C Almeida, ${ }^{3}$ \\ Carlos A de Souza Teles, ${ }^{3}$ Carine S Andrade, ${ }^{3,4}$ Art L Reingold, ${ }^{1}$ \\ Edson D Moreira $\mathrm{Jr}^{2,3}$
}

To cite: G Duarte F, da Silva Moreira S, Almeida MCC, et al. Sex differences and correlates of poor glycaemic control in type 2 diabetes: a cross-sectional study in Brazil and Venezuela. BMJ Open 2019;9:e023401. doi:10.1136/ bmjopen-2018-023401

- Prepublication history for this paper is available online. To view these files, please visit the journal online (http://dx.doi org/10.1136/bmjopen-2018023401).

Received 11 April 2018 Revised 13 December 2018 Accepted 17 December 2018

Check for updates

(C) Author(s) (or their employer(s)) 2019. Re-use permitted under CC BY-NC. No commercial re-use. See rights and permissions. Published by BMJ.

${ }^{1}$ Department of Epidemiology, School of Public Health, University of California, Berkeley, California, USA

${ }^{2}$ Associação Obras Sociais Irmã Dulce, Salvador, Bahia, Brazil

${ }^{3}$ Laboratório de Epidemiologia Molecular e Bioestatística,

Instituto Gonçalo Moniz,

FIOCRUZ-BA, Salvador, BA,

Brazil

${ }^{4}$ Escola de Nutrição,

Departamento Ciências da

Nutrição, Universidade Federal

da Bahia, Salvador, Bahia, Brazil

Correspondence to

Dr Fernanda G Duarte;

nanda_duarte@berkeley.edu

\section{ABSTRACT}

Objective Examine whether glycaemic control varies according to sex and whether the latter plays a role in modifying factors associated with inadequate glycaemic control in patients with type 2 diabetes (T2D) in Brazil and Venezuela.

Design, setting and participants This was a crosssectional, nationwide survey conducted in Brazil and Venezuela from February 2006 to June 2007 to obtain information about glycaemic control and its determinants in patients with diabetes mellitus attending outpatient clinics.

Main outcome measures Haemoglobin A1c (HbA1c) level was measured by liquid chromatography, and patients with $\mathrm{HbA} 1 \mathrm{c} \geq 7.0 \%$ (53 $\mathrm{mmol} / \mathrm{mol}$ ) were considered to have inadequate glycaemic control. The association of selected variables with glycaemic control was analysed by multivariate linear regression, using $\mathrm{HbA} 1 \mathrm{c}$ as the dependent variable.

Results A total of 9418 patients with T2D were enrolled in Brazil $(n=5692)$ and in Venezuela $(n=3726)$. They included 6214 (66\%) women and 3204 (34\%) men. On average, $\mathrm{HbA} 1 \mathrm{c}$ levels in women were $0.13(95 \% \mathrm{Cl} 0.03$ to 0.24 ; $\mathrm{p}=0.015$ ) higher than in men, after adjusting for age, marital status, education, race, country, body mass index, duration of disease, complications, type of healthcare, adherence to diet, adherence to treatment and previous measurement of $\mathrm{HbA} 1 \mathrm{c}$. Sex modified the effect of some factors associated with glycaemic control in patients with T2D in our study, but had no noteworthy effect in others. Conclusions Women with T2D had worse glycaemic control than men. Possible causes for poorer glycaemic control in women compared with men include differences in glucose homeostasis, treatment response and psychological factors. In addition, sex modified factors associated with glycaemic control, suggesting the need to develop specific treatment guidelines for men and women.

\section{INTRODUCTION}

Diabetes mellitus (DM) is a chronic condition characterised by insulin deficiency or impaired response to insulin, leading to hyperglycaemia. ${ }^{1}$ DM directly caused an
Strengths and limitations of this study

- The large multicentre sample, providing statistical power to examine the effects of many variables and to adjust for confounding.

- The measurement of haemoglobin A1c was performed using a reliable method in a central laboratory, avoiding problems with lack of standardisation reported by other authors.

- This study was conducted in health centres, consequently our conclusions may not apply to patients with type 2 diabetes who do not seek medical care or who have not yet been diagnosed.

- Patients' data were collected through interviews, potentially introducing a certain degree of inaccuracy for some answers. However, self-reported data have been shown to have high agreement with medical records for several questions.

- The study design, a cross-sectional survey, is limiting because the temporal relationship between the exposure and the outcome cannot be determined with certainty.

estimated 1.5 million deaths in 2012, making it the world's eight leading cause of death among both sexes and the fifth leading cause among women. ${ }^{2}$ In Latin America, DM is one of the main causes of death among the chronic, non-communicable diseases, only exceeded by myocardial infarction and stroke. ${ }^{3}$ According to the American Diabetes Association (ADA), the most prevalent form is type 2 diabetes (T2D), accounting for approximately $90 \%$ of all cases. ${ }^{4}$

People affected by T2D develop hyperglycaemia gradually and may only have symptoms once their DM is advanced. ${ }^{4}$ Late diagnosis, difficulty in adjusting individual treatment and non-adherence to treatment can lead to severe complications, such as retinopathy, neuropathy, nephropathy, amputation and stroke. ${ }^{5}$ These complications can 
have a significant impact on the individual and at the population level. There is also a financial burden that not only has a significant effect on patients and their families, but on health systems worldwide. Overall, $12 \%$ of global health expenditures are directed at DM and consequent complications. ${ }^{1}$

Complications of DM are avoidable and their likelihood of developing is directly correlated with level of glycaemic control. Evidence from key controlled studies has established the importance of tight and sustained glycaemic control among patients with DM. ${ }^{6-8}$ These studies have emphasised the central role of managing HbA1c levels in these patients, leading professional associations to propose targeting haemoglobin A1c (HbAlc) levels in the range of $6.5 \%-7.0 \%(48-53 \mathrm{mmol} / \mathrm{mol}){ }^{4}$

It has been shown that women with DM are generally less likely to reach target levels of HbA1c and, therefore, have more difficulties achieving adequate glycaemic control compared with men. ${ }^{9-16}$ Possible reasons for the different outcomes between men and women are differences in glucose and energy homeostasis (eg, hormones and visceral adipose distribution), ${ }^{17}$ treatment response (eg, side effects) and psychological factors (eg, acceptance of disease) ${ }^{18}$ Despite the potential role of sex on glycaemic control, currently, there are no specific treatment guidelines for men and women with T2D.

There are few publications in the medical literature reporting on the factors associated with glycaemic control in patients with T2D in South American countries. ${ }^{19-21}$ There is also a dearth of studies describing the role sex differences may have on these factors. ${ }^{22}$ Here, we combined data collected in two large surveys on the prevalence of glycaemic control ${ }^{2123}$ to further examine whether glycaemic control varies according to sex, and whether the latter modifies factors associated with glycaemic control in patients with T2D in Brazil and Venezuela.

\section{METHODS}

\section{Study design and centre selection}

We used data from two nationwide surveys on the prevalence of glycaemic control conducted in Brazil and Venezuela from February 2006 to June 2007. Detailed information on study design and methods has been published elsewhere. ${ }^{23}$ Briefly, the surveys were conducted in outpatient diabetes clinics and obtained detailed information about glycaemic control and its determinants in a large sample of adults with DM in Brazil and in Venezuela. Overall, 52 centres participated in the study in Brazil $(n=20)$ and Venezuela $(n=32)$. For the selection of diabetes centres, we asked the Brazilian Diabetes Association and two Venezuelan diabetes associations (Venezuelan Endocrinology Society and La Federación Nacional de Asociaciones y Unidades de Diabetes-FENADIABETES) to identify, in each of the regions studied, a minimum of four candidate centres from various registries, patient association lists and professional information. These centres were to be chosen from those with longer experience in epidemiological research and where at least 100 adult patients with diabetes were followed per month. They were classified as university-affiliated hospitals (20), public general hospitals (15) or private not-for-profit hospitals (17).

\section{Study population}

A sample of all consecutive patients with DM attending each participating clinic during a 30-day period was selected. Eligible cases were adults aged $\geq 18$ years who had been previously diagnosed by a physician with either type 1 diabetes or T2D before the survey (for the current analysis, only T2D were included). Patients who had participated in an intervention trial in the previous 3 months and women who reported a history of diabetes only during pregnancy were excluded. Each centre was asked to recruit at least 150 patients. Overall, the response rates were $84 \%$ (78\%-95\%) in Brazil and 92\% (85\%-98\%) in Venezuela.

\section{Ethical considerations}

All patients were informed about the study aims, procedures and risks and signed an informed consent prior to inclusion. The study protocol was carried out in accordance with the principles of the Declaration of Helsinki as revised in 2000 .

\section{Data collection}

Data were collected using different strategies: a structured questionnaire (including self-reported items) and a blood sample to measure HbAlc. The information on sociodemographic characteristics (ie, age, sex, race, marital status and education), DM history, current medications, self-reported symptoms and comorbid conditions, complications and clinical parameters (ie, fasting blood glucose, HbAlc and body mass index (BMI)) were gathered using a structured questionnaire. In addition, data on factors related to treatment processes, such as self-reported adherence to diet and treatment, patient perception of treatment convenience and factors related to healthcare access (eg, number of consultations in the previous year, whether seen by the same physician, private or public healthcare) were obtained. Information was also collected on self-rated glycaemic control (using a scale with five levels: poor, fair, good, very good and excellent) and satisfaction with current diabetes treatment (using a single global question: 'If you were to spend the rest of your life with your diabetes treatment the way it is today, how would you feel about this? Very satisfied, somewhat satisfied, neither dissatisfied nor satisfied, somewhat dissatisfied, or very dissatisfied').

\section{Patient and public involvement}

A round of pilot testing was conducted prior to data collection on a sample of volunteer patients $(n=30)$, in both Brazil and Venezuela, to assess and improve question wording and interviewer performance. The pilot interviews were recorded, and then four reviewers listened 
to each interview and documented potential issues in question presentation or comprehension. Health survey experts assessed all items for face validity. The individual interviews lasted an average $20-25 \mathrm{~min}$, and the sessions occurred in a private room. The study questionnaire was administered in person by a team of trained and certified interviewers (not part of the local centre staff).

\section{Measurement of glycated haemoglobin}

A peripheral blood sample was collected for the measurement of HbA1c in every patient. All measurements of HbAlc were made by automated high-performance liquid chromatography (Variant Turbo-BioRad) in a central laboratory for each country. The normal value range was $4.0 \%-6.0 \%(20-42 \mathrm{mmol} / \mathrm{mol})$.

\section{Statistical analysis}

Patients with $\mathrm{HbAlc} \geq 7.0 \%$ ( $53 \mathrm{mmol} / \mathrm{mol}$ ) were considered to have inadequate glycaemic control. ${ }^{4}$ Initially, a descriptive analysis was performed; the factors possibly associated with inadequate glycaemic control were evaluated using univariate linear regression, with the value of HbA1c as the dependent variable. Next, data from men and women were fit into multivariate linear regression models separately, starting with the same set of independent variables and using backwards elimination to fit the best model. In this step, variables with a value of $\mathrm{p}<0.10$ in either regression model (man or woman) were kept. Sociodemographic variables (eg, age, marital status, education and race) were kept in the model regardless of the significance level. To assess for effect modification by sex, we checked whether the point estimate of an independent variable in the regression model for one sex was not included in the respective $95 \%$ CI of the same variable in the regression model for the other sex. The statistical analyses were performed using the STATA statistical software V.12).

\section{RESULTS}

A total of 9418 patients with T2D were enrolled in Brazil $(\mathrm{n}=5692)$ and Venezuela $(\mathrm{n}=3726)$. They included 6214 $(66 \%)$ women and $3204(34 \%)$ men (table 1). Ages ranged from 18 to 98 years; most of the study participants were married or living with a partner, of white race and had completed primary school education or less. The distribution of BMI categories among male patients showed that $44.5 \%$ were overweight and $25.8 \%$ were obese compared with $36.2 \%$ and $35.2 \%$ among female patients, respectively. Less than one quarter of the study participants reported no complications of DM; approximately half reported poor/fair adherence to diet and self-rated their glycaemic control as very good/excellent; roughly three quarters $(73.6 \%)$ were either satisfied or very satisfied with their current DM treatment.

The prevalence of inadequate glycaemic control was $74.2 \%$ and $73.0 \%$ among female and male patients with T2D, respectively. The average HbAlc level was higher among women $(8.8 \%)(73 \mathrm{mmol} / \mathrm{mol})$ than in men $(8.6 \%)(70 \mathrm{mmol} / \mathrm{mol})(\mathrm{p}=0.002)$. In the adjusted analysis, the average difference between HbAlc levels in women and men was 0.13 (95\% CI 0.03 to $0.24 ; \mathrm{p}=0.015)$. Table 2 shows the results of the multivariate analysis of factors potentially associated with glycaemic control according to sex. Increasing age in years was associated with better glycaemic control in both men and women. Non-white race was a predictor of worse control of DM. Subjects with a higher level of education (some college) or residing in Brazil were more likely to have a lower HbA1c level. Regarding BMI, men in the underweight category had worse glycaemic control than those of normal weight, but this difference was not observed among women. Obesity and overweight were predictors of lower HbAlc levels in both sexes. Duration of T2D was positively correlated with HbAlc in both men and women, as well as the number of complications in women with T2D. Men and women who sought a private healthcare service to treat their T2D in the past 12 months had lower HbAlc levels compared with those who used only public clinics. Better adherence to diet (self-reported) was also associated with improved glycaemic control, while adherence to treatment was not. Having had HbAlc measured in the past 12 months was associated with better glycaemic control in women, while men who perceived their diabetes treatment as convenient, compared with those who did not, were more likely to have a lower level of HbAlc. In both men and women, self-rated glycaemic control was associated with lower levels of HbA1c.

The magnitude of the association between some factors (ie, age, race, education, self-reported adherence to diet, and self-rated glycaemic control) and glycaemic control was similar in both men and women, while for other factors (ie, country of residence, BMI, T2D duration, number of complications, access to private healthcare, HbA1c measurement in the past year and perception of treatment convenience), the magnitude of the association seemed different for men as compared with women, therefore, suggesting that their effect was modified by sex.

\section{DISCUSSION}

We found that women with T2D had significantly higher HbA1c levels than men, after adjusting for several potential confounders. Furthermore, our results have shown that sex modifies determinants of glycaemic control, suggesting that specific treatment guidelines for men and women may be helpful. Some demographic and lifestyle characteristics might have changed in the study population since the data were collected, but the biological differences between sexes have likely remained. Thus, the correlates identified here might still be present.

Our findings are consistent with those of previous studies. In 2002, a survey of 21277 patients with diabetes between the ages of 45 and 64 years in Israel showed better glycaemic control in men, despite lower healthcare 
Table 1 Characteristics (\%) of 9418 patients with T2D in Brazil and Venezuela

\begin{tabular}{|c|c|c|c|c|c|c|}
\hline & \multicolumn{3}{|l|}{ Men } & \multicolumn{3}{|l|}{ Women } \\
\hline & Brazil & Venezuela & Total & Brazil & Venezuela & Total \\
\hline & $\begin{array}{l}n=1904 \\
(59 \%)\end{array}$ & $\begin{array}{l}n=1300 \\
(41 \%)\end{array}$ & $\begin{array}{l}n=3204 \\
(100 \%)\end{array}$ & $\begin{array}{l}n=3788 \\
(61 \%)\end{array}$ & $\begin{array}{l}n=2426 \\
(39 \%)\end{array}$ & $\begin{array}{l}n=6214 \\
(100 \%)\end{array}$ \\
\hline \multicolumn{7}{|c|}{ Age (years) } \\
\hline $18-34$ & 0.7 & 1.9 & 1.2 & 1.1 & 1.9 & 1.4 \\
\hline $55-64$ & 36 & 31 & 34 & 34 & 33 & 34 \\
\hline$\geq 65$ & 36 & 32 & 35 & 38 & 33 & 36 \\
\hline
\end{tabular}

Marital status

\begin{tabular}{|c|c|c|c|c|c|c|}
\hline Married/living with partner & 77 & 71 & 75 & 49 & 47 & 48 \\
\hline Single & 10 & 18 & 13 & 16 & 26 & 20 \\
\hline Separated/divorced & 8 & 6 & 7 & 9 & 9 & 9 \\
\hline Widowed & 5 & 5 & 5 & 25 & 18 & 22 \\
\hline \multicolumn{7}{|l|}{ Race/ethnicity } \\
\hline White & 49 & 43 & 46 & 43 & 48 & 45 \\
\hline Mixed & 29 & 52 & 39 & 29 & 48 & 37 \\
\hline Black & 10 & 4 & 8 & 14 & 3 & 10 \\
\hline Others & 12 & 0.1 & 7 & 14 & 1.0 & 9 \\
\hline
\end{tabular}

Education

\begin{tabular}{|c|c|c|c|c|c|c|}
\hline Primary school or less & 64 & 42 & 55 & 77 & 59 & 70 \\
\hline Middle school/high school & 23 & 37 & 28 & 17 & 29 & 21 \\
\hline Some college & 13 & 22 & 17 & 6 & 12 & 9 \\
\hline Underweight ( $\leq 18.5)$ & 1.1 & 0.5 & 0.8 & 1.8 & 0.9 & 1.4 \\
\hline Normal weight (18.6-24.9) & 30 & 27 & 29 & 28 & 25 & 27 \\
\hline Obesity ( $\geq 30.0)$ & 23 & 30 & 26 & 34 & 37 & 35 \\
\hline Patients with $\mathrm{HbA} 1 \mathrm{c} \geq 7.0(\%)$ & 72 & 75 & 73 & 74 & 75 & 74 \\
\hline \multicolumn{7}{|l|}{ Complications from diabetes } \\
\hline None & 24 & 24 & 24 & 24 & 21 & 23 \\
\hline \multicolumn{7}{|l|}{ Self-reported adherence to diet } \\
\hline Poor & 25 & 25 & 25 & 19 & 21 & 20 \\
\hline Fair & 32 & 35 & 33 & 34 & 38 & 35 \\
\hline Good & 28 & 30 & 29 & 29 & 32 & 30 \\
\hline Excellent & 16 & 10 & 14 & 18 & 9 & 15 \\
\hline
\end{tabular}

Self-rated glycaemic control

\begin{tabular}{lllllll} 
Poor & 6 & 5 & 6 & 7 & 3 & 5 \\
Fair & 5 & 5 & 5 & 8 & 4 & 6 \\
\hline Good & 42 & 37 & 40 & 42 & 37 & 40 \\
Very good & 39 & 43 & 40 & 36 & 47 & 40 \\
Excellent & 8 & 11 & 9 & 8 & 9 & 8 \\
\hline
\end{tabular}




\begin{tabular}{|c|c|c|c|c|c|}
\hline Men & & & Women & & \\
\hline Brazil & Venezuela & Total & Brazil & Venezuela & Total \\
\hline $\begin{array}{l}n=1904 \\
(59 \%)\end{array}$ & $\begin{array}{l}n=1300 \\
(41 \%)\end{array}$ & $\begin{array}{l}n=3204 \\
(100 \%)\end{array}$ & $\begin{array}{l}n=3788 \\
(61 \%)\end{array}$ & $\begin{array}{l}n=2426 \\
(39 \%)\end{array}$ & $\begin{array}{l}n=6214 \\
(100 \%)\end{array}$ \\
\hline
\end{tabular}

Global satisfaction with current treatment

\begin{tabular}{lllllll} 
Very unsatisfied & 1.7 & 2.0 & 1.8 & 1.9 & 1.0 & 1.6 \\
\hline Unsatisfied & 8 & 6 & 7 & 10 & 6 & 8 \\
\hline Neutral & 16 & 19 & 17 & 16 & 18 & 17 \\
\hline Satisfied & 61 & 61 & 61 & 59 & 65 & 61 \\
Very satisfied & 14 & 13 & 14 & 13 & 11 & 12 \\
\hline
\end{tabular}

T2D, type 2 diabetes.

utilisation. ${ }^{9}$ A study of 229 Swedish primary healthcare centres, enrolling 9375 subjects (5082 men and 4293 women) with diabetes, found that men had better glycaemic control (HbAlc $\leq 6.5 \% / 48 \mathrm{mmol} / \mathrm{mol}$ ) than women. ${ }^{12}$ A cross-sectional study including 3849 patients with diabetes in the USA in 2003 found that women were less likely than men to have $\mathrm{HbAlc}<7 \%$ ( $53 \mathrm{mmol} / \mathrm{mol}$ ) after adjusting for age, sociodemographic variables and clinic site. ${ }^{13}$ Data from the Health and Retirement Study of 1619 adults with T2D in 2010 also showed that women had worse glycaemic control compared with men, even though women reported better adherence to diet and blood glucose self-monitoring behaviours than men. ${ }^{11}$

In contrast, other studies have found no significant relationship between sex and glycaemic control. For example, a study of 180 patients with T2D from two health clinics in Texas in 2007 found no sex differences in glycaemic control, after adjusting for self-management behaviours and quality of life indicators, suggesting that sex differences in glycaemic control outcomes might be related to less perceived social support, less acceptance of disease and more difficulty in self-management behaviour in women. ${ }^{25}$ A cross-sectional study in the UK in 2002 of 10663 patients with T2D aged 17-98 years ${ }^{5}$ and another one in Canada with 5569 patients ${ }^{26}$ also found no association between sex and HbAlc levels.

Possible causes for poorer glycaemic control in women compared with men include differences in regulation of glucose homeostasis, ${ }^{17}$ treatment response and psychological factors. ${ }^{18}$ A survey of 201 Pakistani patients with T2D living in Manchester, UK, showed that women were worse than men in performing glucose self-measurements and in managing persistent hyperglycaemia, and consequently, had poorer glycaemic control overall. ${ }^{15}$ Salcedo-Rocha et al in Mexico suggested that women had several social and economical disadvantages (ie, lower education, lower participation in paid work, and reduced wages or economic dependence) that might decrease their ability to achieve glycaemic control successfully. ${ }^{16}$ Women and men differ in the distribution of body fat and in hormonal production, both of which are likely to alter the risk of developing T2D and its complications. Obesity and being overweight are two of the strongest risk factors for developing T2D in both sexes, ${ }^{22}$ and women are even more vulnerable, as they have a higher percentage of body fat than men. ${ }^{27}$ In addition, $40 \%$ of men with T2D have abdominal obesity, compared with $70 \%$ of women, suggesting a stronger association between T2D and abdominal obesity in women than in men. ${ }^{28}$

Sex hormones not only regulate sex characteristics and fertility, but are essential in regulating glucose homeostasis and are responsible for fundamental biological differences between men and women. ${ }^{29} 30$ Testosterone in men stimulates lipolysis in adipose tissue, so low testosterone levels are associated with abdominal obesity and insulin resistance. ${ }^{29}$ A meta-analysis in 2006 that reviewed 80 articles examining sex differences in endogenous hormones and the risk of T2D found that men with higher testosterone levels $(15.6-21.0 \mathrm{nmol} / \mathrm{L})$ had a $42 \%$ lower risk of developing T2D. They found the opposite was true for women, for whom, increased androgen levels were associated with insulin resistance and an increased risk of T2D. ${ }^{31}$ Oestrogen is the primary female hormone, is synthesised in the ovaries in women before menopause and in adipose tissue in both men and women via conversion from testosterone. ${ }^{32}$ In women, the decrease in oestrogen levels after menopause occurs concurrently with increased elevated blood glucose levels, whereas in men, elevated oestrogen levels may be a risk factor for insulin resistance. $^{33}$

There are also metabolic differences between men and women in the pharmacodynamics of the medications used to treat T2D. Metformin, an oral hypoglycaemic drug, has been shown to have more beneficial effects on myocardial fatty acid and glucose metabolism in men than in women. ${ }^{34}$ Women were found to report more adverse effects than men when treated with this medication $(15 \%$ vs $10 \%)$ and were also less adherent to treatment. ${ }^{35}$ Women may also be more likely to experience side effects from thiazolidinediones (insulin-sensitising drugs), experiencing more hypoglycaemia ${ }^{36}$ and bone fractures. ${ }^{37}$ In patients treated with insulin, hypoglycaemia is not only more 
Table 2 Multivariate linear regression of HbA1c level in men and women with T2D in Brazil and Venezuela

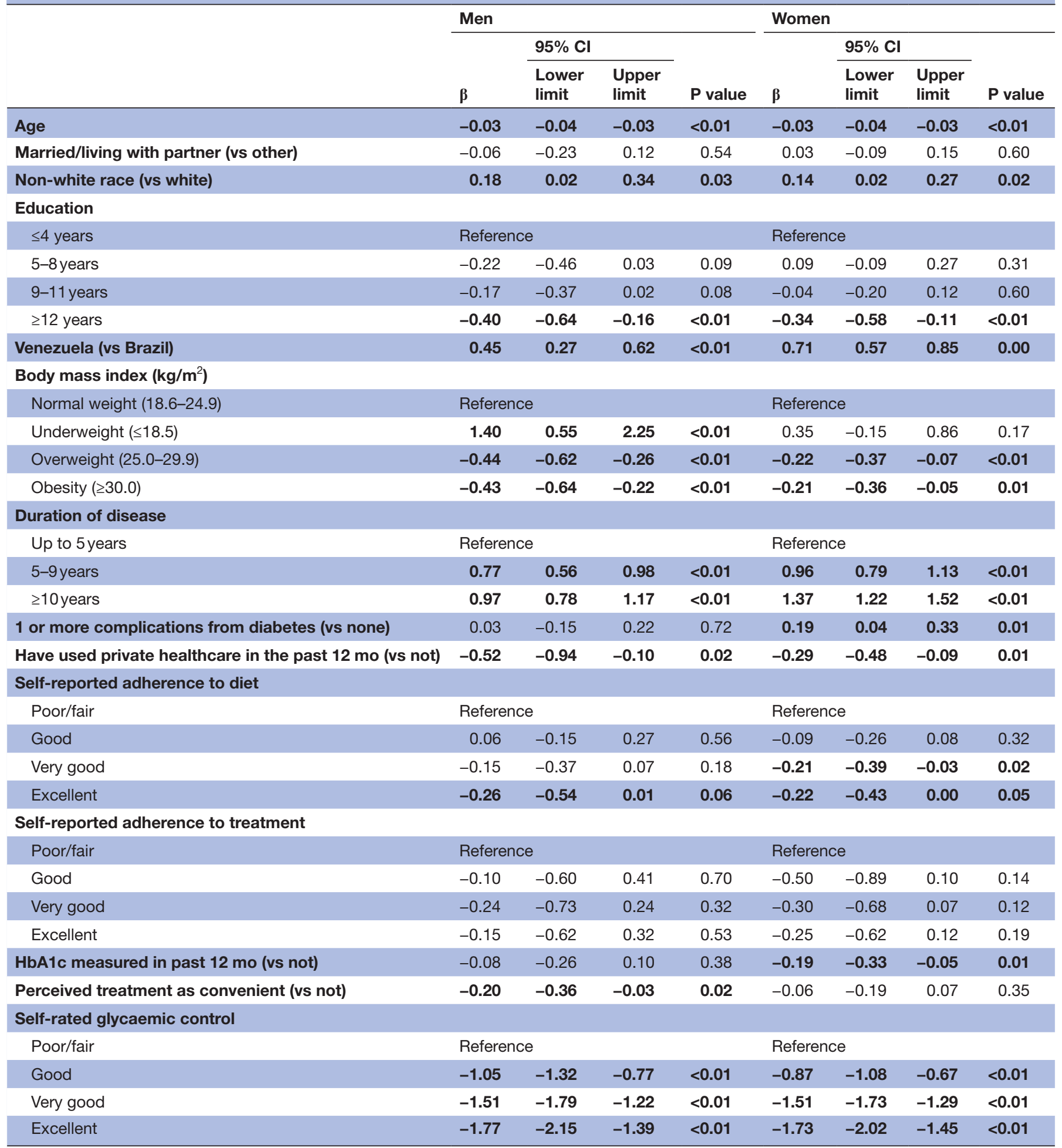

HbA1c, haemoglobin A1c; T2D, type 2 diabetes.

Statistically significant values are shown in bold.

common, but also more severe in women. ${ }^{38}$ This difference may, in part, be explained by women having lower counter-regulatory responses to hypoglycaemia. ${ }^{39}$ One of the reasons for poorer adherence to more intensive insulin treatment and other antidiabetic medications in women may be due to fear of these side effects. ${ }^{40}$
Psychological factors, such as depression, stress and anxiety, affect men and women differently and potentially contribute to poor glycaemic control. A cross-sectional study of 8871 subjects in Germany in 2013 showed that social class and psychosocial stress were stronger predictors of T2D in women than in men. ${ }^{41}$ According to a study 
in 2013 by Siddiqui et al, which reviewed the differences between men and women in coping with DM, men with DM were more satisfied with the management of their disease and experienced less depression and anxiety, compared with women with DM. ${ }^{42}$ Women with T2D were also found to have a higher prevalence of depression than women without T2D. ${ }^{43}$

Given that women tend to have worse control of their T2D, it is important to assess whether determinants of glycaemic control affect men and women differently. Sex modified the effect of some factors associated with glycaemic control in patients with T2D in our study but had no noteworthy effect in others. Patients with T2D living in Venezuela had worse glycaemic control than those living in Brazil. Healthcare disparities between these countries may account for this difference, and our results suggest that women are affected by these inequalities to a higher extent than men. The relationship between BMI and glycaemic control was also modified by sex. It is plausible that differences of body fat distribution in men and women may lead to a different impact on outcomes of glycaemic control. ${ }^{27}$ Predictors of worse glycaemic control (eg, longer duration of disease and presence of complications) also seemed to affect women to a higher degree than men. Menopause predisposes women to hyperglycaemia ${ }^{33} 44$ and is more prone to drug side effects. ${ }^{34}$ Therefore, they may be more affected by diabetes duration and related complications. Predictors of better glycaemic control were modified by sex in different ways. While access to private care and perception of treatment as convenient seemed to have a greater effect in men as compared with women, the opposite was observed for another predictor of better glycaemic control (HbAlc measurement in the past year). More studies are warranted to better assert these findings.

This study had limitations. It was conducted in health centres, consequently our conclusions may not apply to patients with T2D who do not seek medical care or who have not yet been diagnosed. Patients' data were collected through interviews, potentially introducing a certain degree of inaccuracy for some answers. However, self-reported data have been shown to have high agreement with medical records for several questions, such as type of diabetes, family history of diabetes, therapeutic regimen and disease complications. ${ }^{45}$ Finally, the study design, a cross-sectional survey, is limiting because the temporal relationship between the exposure and the outcome cannot be determined with certainty. The strengths of this study are the large multicentre sample, providing statistical power to examine the effects of many variables and to adjust for confounding. Another merit was the collection of data by trained and certified interviewers, who were not part of the staff at the study centres, avoiding patients feeling uncomfortable about truthfully reporting on adherence to diet or treatment. Last, the measurement of HbAlc was performed using a reliable method in a central laboratory.

\section{CONCLUSIONS}

We have shown that women with T2D had worse glycaemic control than men. In addition, sex modified factors associated with glycaemic control suggesting the need of specific treatment guidelines for men and women. These data may be helpful to improve strategies and policies aimed at minimising the complications of T2D in men and women with T2D. Longitudinal studies are warranted and may help elucidate whether the factors we found to be associated with higher HbA1c levels are indeed causally related to poor glycaemic control.

Acknowledgements The authors wish to thank all the study investigators and staff in Brazil and Venezuela for their valuable contributions. SdSM received a scholarship from the Coordination for the Improvement of Higher Education Personnel (CAPES), Brazilian Ministry of Education. EDMJ received support from the National Council for Scientific and Technological Development (CNPq).

Contributors Conceived and designed the study: EDM and FGD. Analysis and interpretation of data: FGD, SdSM, ALR, CAdST and EDM. Wrote the first draft: FGD. Reviewed and approved the final version of the manuscript: All authors.

Funding The study was supported by an unconditional grant from Pfizer Inc. The Brazilian Study of Diabetes Control was funded by Pfizer Inc., Brazil.

Competing interests EDM reports having received grant support through his institution from Pfizer Inc.

Ethics approval The study protocol was approved by the Hospital Santo Antônio Ethics Committee (approval number 32/05).

Provenance and peer review Not commissioned; externally peer reviewed.

Data sharing statement The datasets analysed during the current study may be available from the corresponding author on reasonable request.

Open access This is an open access article distributed in accordance with the Creative Commons Attribution Non Commercial (CC BY-NC 4.0) license, which permits others to distribute, remix, adapt, build upon this work non-commercially, and license their derivative works on different terms, provided the original work is properly cited, appropriate credit is given, any changes made indicated, and the use is non-commercial. See: http://creativecommons.org/licenses/by-nc/4.0/.

\section{REFERENCES}

1. International Diabetes Federation. IDF Diabetes Atlas. 7 edn, 2015.

2. WHO. Mortality Database: WHO, 2014.

3. WHO. Global Report on Diabetes, 2016.

4. American Diabetes Association. Standards of medical care in diabetes-2016. Diabetes Care 2016;39:S1-112.

5. Fox KM, Gerber Pharmd RA, Bolinder B, et al. Prevalence of inadequate glycemic control among patients with type 2 diabetes in the United Kingdom general practice research database: A series of retrospective analyses of data from 1998 through 2002. Clin Ther 2006;28:388-95.

6. Reichard P, Berglund B, Britz A, et al. Intensive blood-glucose control with sulphonylureas or insulin compared with conventional treatment and risk of complications in patients with type 2 diabetes (UKPDS 33). UK Prospective Diabetes Study (UKPDS) Group. Lancet 1998;352:837-53.

7. Nathan DM, Genuth S, Lachin J, et al. The effect of intensive treatment of diabetes on the development and progression of longterm complications in insulin-dependent diabetes mellitus. $N$ Engl J Med 1993;329:977-86.

8. Sousa Andrade C, Sousa Ribeiro G. Factors associated with high levels of glycated haemoglobin in patients with type 1 diabetes: a multicentre study in Brazil. BMJ Open 2017.

9. Shalev V, Chodick G, Heymann AD, et al. Gender differences in healthcare utilization and medical indicators among patients with diabetes. Public Health 2005;119:45-9.

10. Tang YH, Pang SM, Chan MF, et al. Health literacy, complication awareness, and diabetic control in patients with type 2 diabetes mellitus. J Adv Nurs 2008;62:74-83.

11. Chiu CJ, Wray LA. Gender differences in functional limitations in adults living with type 2 diabetes: biobehavioral and psychosocial mediators. Ann Behav Med 2011;41:71-82. 
12. Nilsson PM, Theobald H, Journath $\mathrm{G}$, et al. Gender differences in risk factor control and treatment profile in diabetes: a study in 229 swedish primary health care centres. Scand J Prim Health Care 2004:22:27-31.

13. Wexler DJ, Grant RW, Meigs JB, et al. Sex disparities in treatment of cardiac risk factors in patients with type 2 diabetes. Diabetes Care 2005;28:514520:514-20.

14. Kamuhabwa AR, Charles E. Predictors of poor glycemic control in type 2 diabetic patients attending public hospitals in Dar es Salaam. Drug Healthc Patient Saf 2014;6:155-65.

15. Hawthorne K, Tomlinson S. Pakistani moslems with Type 2 diabetes mellitus: effect of sex, literacy skills, known diabetic complications and place of care on diabetic knowledge, reported self-monitoring management and glycaemic control. Diabet Med 1999;16:591-7.

16. Salcedo-Rocha AL, García de Alba-García JE, Frayre-Torres MJ, et al. [Gender and metabolic control of type 2 diabetes among primary care patients]. Rev Med Inst Mex Seguro Soc 2008;46:73-81.

17. Mauvais-jarvis F. Physiology \& Behavior Gender di ff erences in glucose homeostasis and diabetes. 2018;187:20-3.

18. Arnetz L, Ekberg NR, Alvarsson M. Sex differences in type 2 diabetes: focus on disease course and outcomes. Diabetes Metab Syndr Obes 2014;7:409.

19. Moreira ED, Neves RCS, Nunes ZO, et al. Glycemic control and its correlates in patients with diabetes in Venezuela: Results from a nationwide survey. Diabetes Res Clin Pract 2010;87:407-14.

20. Moreira ED, Silveira PC, Neves RC, et al. Glycemic control and diabetes management in hospitalized patients in Brazil. Diabetol Metab Syndr 2013;5:62.

21. Mendes AB, Fittipaldi JA, Neves RC, et al. Prevalence and correlates of inadequate glycaemic control: results from a nationwide survey in 6,671 adults with diabetes in Brazil. Acta Diabetol 2010;47:137-45.

22. Legato MJ, Gelzer A, Goland R, et al. Gender-specific care of the patient with diabetes: review and recommendations. Gend Med 2006;3:131-58.

23. Moreira ED, Neves RC, Nunes ZO, et al. Glycemic control and its correlates in patients with diabetes in Venezuela: results from a nationwide survey. Diabetes Res Clin Pract 2010;87:407-14.

24. Bahia LR, Araujo DV, Schaan BD, et al. The costs of type 2 diabetes mellitus outpatient care in the Brazilian public health system. Value Health 2011;14:S137-S140.

25. Misra R, Lager J, Aalto AM. Ethnic and gender differences in psychosocial factors, glycemic control, and quality of life among adult type 2 diabetic patients. J Diabetes Complications 2009;23:54-64.

26. Shah BR, Hux JE, Laupacis A, et al. Diabetic patients with prior specialist care have better glycaemic control than those with prior primary care. J Eval Clin Pract 2005;11:568-75.

27. Mattsson C, Olsson T. Estrogens and glucocorticoid hormones in adipose tissue metabolism. Curr Med Chem 2007;14:2918-24.

28. Pasquali R, Vicennati V, Gambineri A, et al. Sex-dependent role of glucocorticoids and androgens in the pathophysiology of human obesity. Int J Obes 2008;32:1764-79.
29. Navarro G, Allard C, Xu W, et al. The role of androgens in metabolism, obesity, and diabetes in males and females. Obesity 2015;23:713-9.

30. Mauvais-Jarvis F, Clegg DJ, Hevener AL. The role of estrogens in control of energy balance and glucose homeostasis. Endocr Rev 2013;34:309-38.

31. Ding EL, Song Y, Malik VS, et al. Sex differences of endogenous sex hormones and risk of type 2 diabetes: a systematic review and metaanalysis. JAMA 2006;295:1288-99.

32. Regitz-Zagrosek V, Lehmkuhl E, Mahmoodzadeh S. Gender aspects of the role of the metabolic syndrome as a risk factor for cardiovascular disease. Gend Med 2007;4 Suppl B:S162-S177.

33. Szalat A, Auryan S, Raz I, et al. Gender-specific care of diabetes mellitus: particular considerations in the management of diabetic women. Diabetes Obes Metab 2008;10:080520205432340-???

34. Lyons MR, Peterson LR, McGill JB, et al. Impact of sex on the heart's metabolic and functional responses to diabetic therapies. $\mathrm{Am} \mathrm{J}$ Physiol Heart Circ Physiol 2013;305:H1584-H1591.

35. Walker EA, Molitch M, Kramer MK, et al. Adherence to preventive medications: predictors and outcomes in the diabetes prevention program. Diabetes Care 2006;29:1997-2002.

36. Vlckova V, Cornelius V, Kasliwal R, et al. Hypoglycaemia with pioglitazone: analysis of data from the prescription-event monitoring study. J Eval Clin Pract 2010;16:1124-8.

37. Kahn SE, Zinman B, Lachin JM, et al. Rosiglitazone-associated fractures in type 2 diabetes: an Analysis from A Diabetes Outcome Progression Trial (ADOPT). Diabetes Care 2008;31:845-51.

38. Rincon J, Holmäng A, Wahlström EO, et al. Mechanisms behind insulin resistance in rat skeletal muscle after oophorectomy and additional testosterone treatment. Diabetes 1996;45:615-21.

39. Amiel SA, Maran A, Powrie JK, et al. Gender differences in counterregulation to hypoglycaemia. Diabetologia 1993;36:460-4.

40. Körner A, Wabitsch M, Seidel B, et al. Adiponectin expression in humans is dependent on differentiation of adipocytes and downregulated by humoral serum components of high molecular weight. Biochem Biophys Res Commun 2005;337:540-50.

41. Müller G, Hartwig S, Greiser KH, et al. Gender differences in the association of individual social class and neighbourhood unemployment rate with prevalent type 2 diabetes mellitus: a cross-sectional study from the DIAB-CORE consortium. BMJ Open 2013;3:e002601

42. Siddiqui MA, Khan MF, Carline TE. Gender differences in living with diabetes mellitus. Mater Sociomed 2013;25:140-2.

43. Anderson RJ, Freedland KE, Clouse RE, et al. The prevalence of comorbid depression in adults with diabetes: a meta-analysis. Diabetes Care 2001;24:1069-78.

44. Mauvais-Jarvis F, Manson JE, Stevenson JC, et al. Menopausal hormone therapy and type 2 diabetes prevention: evidence, mechanisms, and clinical implications. Endocr Rev 2017;38:173-88.

45. Løvaas KF, Cooper JG, Sandberg S, et al. Feasibility of using selfreported patient data in a national diabetes register. BMC Health Serv Res 2015;15:553. 